\title{
19 - Tempo
}

\section{J esuítas e M edicina no B rasil Colonial $^{*}$}

\section{Daniela B uono Calainho**}

O objetivo deste artigo é anal isar a ação dos jesuítas na área da saúde no B rasil colonial. O s inacianos incorporaram esta tarefa aos árd uos ideais missionários e educacionais, mantendo em seus colégios boticas e enfermarias e atuando informalmente como físicos, sangradores e até cirurgiões. A escassez de médicos, pelo menos até o século XVIII, o al to preço das drogas e dos remédios oriundos de Portugal e do O riente e a sua freqüente deterioração nos navios e nos portos obrigaram-nos a se vol tarem para os recursos naturais oferecidos pela terra e para os saberes curativos dos indígenas.

Palavras-chave: J esuítas- C atequese- M edicina

The $J$ esuits and the $C$ urative $A$ rts in Colonial B razil

$T$ his article considers the J esuit action in the health domain and the healing arts in colonial B razil. T he curing hands of the J esuits were a great anchor to colonial health. Since the beginning of its establishment and organization, the Company of J esus in B razil have incorporated this task among its arduous missionary and educational goals by keeping pharmacies and infirmaries in its colleges. The scarcity of licensed physicians trained in the medical schools of E urope, at least until the eighteenth century, the high price of drugs and remedies coming from Portugal and the E ast, and their frequent deterioration en route on merchant ships and in port warehouses, obliged the colonial physicians to revert to local natural resources and to the healing knowledge of the indigenous people.

Key words: Jesuits - M edicine - Christianity

\footnotetext{
${ }^{*}$ Artigo recebido em fevereiro de 2005 e aprovado para publicação em abril de 2005.

${ }^{* *}$ Professora Adjunta do D epartamento de Ciências H umanas da U ERJ -FF P. E-mail: calainho@globo.com

Tempo, Rio de Janeiro, no 19, pp. 61-75
} 
L es J ésuites et la médecine au B résil colonial

Cet article analyse l'action des jésuites dans la médecine au Brésil colonial. L es ignaciens ont incorporé cette tâche a ses idéaux missionnaires et éducatifs en maintenant des pharmacies et des enfermeries dans leurs collèges, aussi que en agissant informellement en tant que physiciens, saigneurs et même chirurgiens. L e manque de médecins, du moins jusqu'au XVIII e siècle, le prix excessif des drogues et des médicaments provenant du Portugal et d'O rient, bien que son habituelle déterioration dans les vaisseaux et dans les ports, les ont obligé a se tourner vers les ressources naturelles et les connaissances de la pharmacopée indienne.

$M$ ots-clefs: Jésuites- $C$ atéchèse-M édicine

F ormada em 1540, por iniciativa de Inácio de L oyola, a Companhia de J esus se configurou como uma ordem-modelo de um novo momento da cristandade na E uropa. O início dos chamados Tempos M odernos foi de grande renovação espiritual, caracterizado por uma ofensiva da I greja romana em deter o avanço protestante através da reafirmação de seus dogmas e sacramentos, da hierarquia eclesiástica, da disciplina do clero e do combate a resquícios de paganismo, superstições e comportamentos sexuais vistos como desviantes. D esenhava-se, assim, um amplo projeto de cristianização das massas, de reordenação social e moral, ancorado nos valores legitimamente cristãos, e a Companhia de J esus surgia neste contextoํ.

E stabelecidos em Portugal, coube aos jesuítas a tarefa missionária e educacional em seus domínios ultramarinos, e sua ação na área da saúde integrou estes ideais, onde quer que se tenham fixado ${ }^{2}$, atuando no tratamento de doenças e epidemias, fundando hospitais, estudando as plantas curativas da região e mantendo eficientes boticas e enfermarias em seus colégios na E uropa, na África, no Oriente e no Brasil³.

\footnotetext{
${ }^{1}$ Ver J ean D elumeau, E I catolicismo de L utero a Voltaire, Barcelona, L abor, 1973, e, ainda, M ichel M ullet, A Contra-R eforma, L isboa, Gradiva, 1984.

¿É vasta a bibliografia sobre os jesuítas no B rasil, da qual citemos o clássico de Serafim L eite, H istória da Companhia deJ esus no B rasil, R io de J aneiro, Civilização B rasileira, 1938, 10 volumes. ${ }^{3}$ Serafim L eite, Ser viços desaúdeda Companhia deJ esusno B rasil (1544-1760), L isboa, Typografia do Porto, 1956, p. 7. M erecem destaque as boticas dos colégios jesuítas no O riente, especialmente em Goa e em M acau, bem como os missionários que para lá se dirigiram, hábeis nas artes médicas e, ao longo do tempo, grandes conhecedores das drogas medicinais da região. Ver o interessante estudo de Ana M aria Amaro, I ntr odução da medicina ocidental em M acao eas receitas de segr edo da botica do Colégio de São Paulo, M acau, I nstituto Cultural de M acau, 1992.
} 
J esuítas e M edicina no B rasil Colonial

Os grandes desafios que se impuseram aos portugueses recém-chegados à então Terra de Santa Cruz foram muitos, como a implantação de uma estrutura administrativa, a progressiva ocu pação territorial, o assentamento dos colonos, a organização dos primeiros engenhos açucarei ros e o enfrentamento de uma geografia, uma flora e uma fauna desconhecidas. Os jesuítas integraram-se ao esforço da travessia atlântica em direção às novas terras americanas. O primeiro G overnador-G eral do Brasil, Tomé de Souza, trouxe consigo, em 1549, al guns inacianos, liderados por M anuel da N óbrega, primeiro Provincial em terras coloniais. Verdadeiro estrategista da catequese, empenhou-se na organização dos aldeamentos para a conversão dos indígenas e na fundação, em 1553, do primeiro estabelecimento de ensino, o Colégio da B ahia, marcando, assim, os ideais que iriam desenvolver no B rasil: a atividade missionária e educacional. A incorporação espiritual do novo território foi missão fundamental a que se dispuseram os jesuítas, viabilizada pelo projeto catequético, expressão de uma vocação universal que caracterizou esta nova cristandade, a partir do século XV, com a expansão do missionarismo 4 .

D esbravadores da natureza indômita do B rasil quinhentista, os soldados da Companhia de J esus enfrentaram duros desafios e árduas condições de subsistência: um clima instável, exércitos de insetos, animais selvagens, peçonhentos e mortíferos, como escorpiões, aranhas e cobras e ainda violentos ataques de grupos de nativos agressivos. Ao lado de um discurso edenizador acerca da natureza colonial, inspiradora de tantos encantamentos, descritos pelas penas de cronistas e viajantes, que louvaram à farta sua opulência e riquezas ${ }^{5}$, os terrores de se viver no T rópico foram também constantemente lembrados. $M$ as a grandiosidade do projeto missionário de conversão do gentio superaria as inúmeras dificuldades com que se depararam estes clérigos. A força destes ideais foi expressa por ninguém menos do que o Pe. Antônio Vieira, quando afirmara que "o português tem obrigação de

${ }^{4} \mathrm{~L}$ uiz F elipe Baeta $\mathrm{N}$ eves, 0 combatedos soldados deCristo na terra dos papagaios, $\mathrm{R}$ io de $J$ aneiro, F orense U niversitária, 1978, pp. 27-28.

${ }^{5} \mathrm{C}$ om um dos exemplos notáveis desta vertente brindou-nos o jesuíta R ocha Pita, para quem o B rasil, "melhor porção do N ovo M undo", era "vastíssima região, felicíssimo terreno em cuja superfície tudo são frutos, em cujo centro tudo são tesouros, em cujas montanhas e costas tudo são aromas". Sebastião da R ocha Pitta, H istória da América Portuguesa (1730), L isboa, E ditor F rancisco Artur da Silva, 1880, pp. 1-2. Ver L aura de M ello e Souza, 0 diabo ea terra de Santa Cruz, São Paulo, Companhia das L etras, 1986, p. 37. 0 clássico de Sérgio Buarque de H olanda, Visões do P araíso, São Paulo, B rasiliense, 1992, é pioneiro e brilhante nesta discussão. 
ser católico e de ser apostólico. Os outros cristãos têm obrigação de crer a fé; o português tem a obrigação de a crer e mais, de a propagar" 6 .

Além de trabalharem incansavelmente na difusão da fé cristã, os jesuítas também foram uma grande âncora da saúde na colônia, atestada pela vastíssima documentação das correspondências que mantiveram com seus irmãos em Portugal e no B rasil. Alguns deles vinham de Portugal já formados nas artes médicas, mas a maioria acabou por atuar informal mente como físicos, sangradores e até cirurgiões, aprendendo, na prática, o ofício na coIônia, como José de Anchieta, J oão Gonçalves ou G regório Serrão. O utros, em meio a obras e cartas, onde comentavam sobre a natureza colonial, dedicaram várias páginas à descrição de ervas e plantas curativas, inaugurando os primeiros escritos sobre a farmacopéia brasileira ${ }^{7}$. F ernão C ardim, por exemplo, descreveu as propriedades curativas de várias espécies de plantas e árvores em seu livro Tratados da terra e gente do B rasil, escrito entre 1583 e 1601, quando desempenhou o cargo de secretário do padre visitador C ristóvão de Gouveiå.

A escassez de médicos leigos, formados por escolas de medicina na E uropa, pelo menos até o século XVIII , fez dos jesuítas os respon sáveis quase que exclusivos pela assistência médica no primeiro século de colonização do Brasi $l^{9}$. Ao longo do tempo, foram aperfeiçoando seus conhecimentos me-

\footnotetext{
${ }^{6}$ E duardo H oonaert, A I greja no B rasil colônia, 1550-1800, São Paulo, Brasiliense, 1982, p. 40.

${ }^{7}$ Ver F ernão Cardim, Gabriel Soares de Souza e M agalhães Gandavo, por exemplo. Para a América espanhola, citemos o F I oril egio M edicinal, de J uan de E steyneffer (1664-1716), publicado no M éxico em 1712, ou o L ibro demedicinas caseras para consuel o delos religiosos y alivio de los enfermos, de F rei Blas de la M adre de D ios, publicado em 1611. H enrique C arneiro, F iltros, mezinhas etriagas. As drogas no mundo moderno, São Paulo, Xamã, 1994, p. 53.

${ }^{8}$ F ernão Cardim, Tratados da terra e gentedo B rasil, L isboa, C omissão para as Comemorações dos D escobrimentos Portugueses, 1997.

${ }^{9}$ Ao contrário de outras fases da história do B rasil, o estudo da medicina no período colonial caracterizou-se até pouco tempo por trabal hos tradicionais, empíricos, bastante úteis, porém carentes de interpretações teórico-metodológicas mais elaboradas. N o entanto, alguns estudos recentemente publicados, como o de M árcia M oisés (A ciência nos trópicos. A artemédica no B rasil do século XVIII , São Paulo, H ucitec, 1997), Vera R egina B eltrão M arques (N atur eza em boiões. M edicinas eboticários no B rasil setecentista, São Paulo, E ditora da U nicamp, 1999) e H enrique $C$ arneiro (Amores esonhos da flora. Afrodisíacos ealucinógenos na botânica ena farmácia, São Paulo, Xamã, 2002), fizeram por articular a uma pesquisa empírica significativa, em arquivos nacionais e estrangeiros, discussões historiográficas e conceitos importantes para a compreensão deste universo, contribuindo para um avanço expressivo na construção do conhecimento histórico deste campo temático.
} 
J esuítas e M edicina no B rasil Colonial

diante contatos com os profissionais leigos residentes na colônia, e ainda pela leitura de importantes obras de medicina, encontradas em muitas das bibliotecas de seus colégios. 0 do $\mathrm{M}$ aranhão, por exemplo, entre seus cerca de 5 mil volumes, vários tomos eram dedicados às artes médicas. Além das obras que vinham de Portugal, muitas foram adquiridas por compra ou doações ${ }^{10}$.

\section{B oticas emedicamentos}

As boticas dos colégios jesuítas foram inigualáveis, em qualquer parte onde estivessem. A do C olégio do Pará, segundo inventário datado de 1760, além de 20 tomos de medicina, continha recipientes diversos, estantes com mais de 400 remédios, fornalhas, alambiques, almofarizes de mármore, ferro e marfim, armários, frascos e potes de várias cores e tamanhos, balanças, pesos, medidas, tachos de cobre, de barro, bacias, prensas, tenazes, enfim, todo um aparato técnico para a confecção dos medicamentos. E com tudo isto era tida como uma botica modesta, comparativamente às existentes nos Colégios da Bahia e do R io de J aneiro ${ }^{11}$. Constituídas em geral por uma sala e uma oficina, tinham ainda uma espécie de loja, onde disponibilizavam seus produtos gratuitamente ao público, salvo para os que tinham melhores condições financeiras e os podiam comprar. O s recursos oriundos destas vendas eram reinvestidos na própria botica e na aquisição de novos medicamentos e livros ${ }^{12}$. E m muitas cidades e vilas, eram as únicas disponíveis e, nas regiões onde existiam outras farmácias, proviam-nas, como foi o caso da botica do Colégio do R io de Janeiro, que, em 1706, era dirigida por um I rmão, com grandes conhecimentos e estudos, e autor de inúmeras receitas ${ }^{13}$. Os inacianos possuíam também embarcações que transportavam remédios ao longo da costa, como foi, por exemplo, o caso do Colégio do M aranhão, que, através de sua "B otica do M ar", abastecia o litoral em direção ao norte, até o Pará14.

\footnotetext{
${ }^{10}$ Serafim L eite, H istória da Companhia deJ esus no B rasil..., op. cit., T omo 4, p. 288.

${ }^{11}$ Idem, p. 190.

${ }^{12} \mathrm{D}$ estaque da presençajesuítica no I mpério português foi a biblioteca do Colégio de $\mathrm{M}$ acau, para onde, em 1616, foram enviados sete mil livros, dos quais quinhentos of ertados pelo Papa. Cf. Ana M aria Amaro, Intr odução da medicina ocidental..., op. cit., p. 10.

${ }^{13} \mathrm{~L}$ icurgo Santos F ilho, H istória geral da medicina brasileira, São Paulo, H ucitec/E dusp, 1991, p. 127.

${ }^{14}$ Serafim L eite, Serviços de saúde.., op. cit., p.14.
} 
Os medicamentos que supriam suas boticas vinham do R eino, mas a pouca freqüência de chegada dos navios, as eventuais perdas por deterioração nas embarcações e nos portos e os al tos preços obrigaram-nos, ao longo do tempo, a se voltarem para os recursos naturais oferecidos pela nova terra, ajudados pelos conhecimentos dos indígenas na decifração desta natureza estranha. Os jesuítas foram exímios observadores da fauna e da flora brasileira, identificando variadas espécies e cultivando as de efeitos curativos. E studavam seu modo de ação para os inúmeros males que acometeram a população colonial, elaborando fórmulas e receitas, organizadas metodicamente com o nome do Colégio onde foram criadas, do autor, dos ingredientes utilizados, o peso e a finalidade ${ }^{15}$.

L evaram para a E uropa o conhecimento das virtudes terapêuticas de raízes, caules, fol has, cascas, sumos, polens, minerais e óleos, a exemplo da quina, planta da região da Amazônia, que curava a malária e era conhecida como "mezinha dos padres da Companhia de Jesus" ${ }^{16}$. A quina chegou a R oma em 1649, levada pelas mãos de um I rmão, e, depois, difundiu-se rapidamente pelo continente; também era chamada de água febrífuga, cuja fórmula básica foi feita no C olégio de Santo Antão, em L isboa ${ }^{17}$. D e igual modo, a ipecacuanha, erva excelente para problemas respiratórios, teve suas virtudes divulgadas na E uropa em 1625, através de um manuscrito de autoria do Pe. F ernão Cardim, onde estavam arroladas várias receitas do I rmão $\mathrm{M}$ anuel Tristão, enfermeiro do Colégio da Bahia ${ }^{18}$. O Pe. M anoel da $\mathrm{N}$ óbrega, por exemplo, remeteu a Portugal al gumas conservas de efeito terapêutico, como suco de ananás verde, para "pedras e areias na urina", recomendando que viessem ao Brasil os que deste mal sofressem. $E$, sobre 0 tabaco, escreveu que "nesta terra do Brasil todas as comidas são difíceis de desgastar, mas $D$ eus remediou isto com uma erva cujo fumo muito ajuda a digestão e outros males corporais e a purgar a fleuma do estômago" ${ }^{19}$.

\footnotetext{
${ }^{15}$ I dem, p.12.

16 "O corre, portanto, desde a descoberta dos novos mundos, uma fusão do saber botânicomédico, que será composto tanto da tradição clássica árabe como das novas plantas e saberes, junto à manuten ção de superstições cristãs". H enrique C arneiro, F iltr os, mezinhas etriagas..., op. cit., p. 66.

${ }^{17} \mathrm{~L}$ ourival R ibeiro, M edicina no B rasil colonial, R io de J aneiro, E ditorial Sul Americana, 1971, p. 156.

${ }^{18}$ L icurgo Santos F ilho, H istória geral da medicina..., op. cit., p. 125.

${ }^{19}$ Serafim L eite, "Os jesuítas no Brasil e a medicina". Separata da Revista Petrus N ominus, L isboa, 1936, p. 13.
} 
J esuítas e M edicina no B rasil Colonial

$D$ as fórmulas medicinais dos inacianos, com uso privativo em suas farmácias, citemos uma compilação, datada de 1766, e de autor até então desconhecido, intitulada Col eção de várias receitas e segr edos particulares das principais boticas da nossa companhia de Portugal, da Í ndia, de M acau e do B rasil, compostas e experimentadas pelos melhores médicos e boticários mais célebres que têm havido nessas partes. Aumentada com al guns índices e notícias muito curiosas e necessárias para a boa direção e acerto contra as enfermidades. E ste extenso receituário, de mais de duzentos títulos, organizado em ordem alfabética, trazia em cada fórmula o nome do colégio onde foi preparada, a dose dos ingredientes, a indicação e o modo de administrá-la. D os C olégios no Brasil, por exemplo, constavam trinta e oito receitas da Bahia ${ }^{20}$, sete do R ecife e duas do R io de J aneiro, a partir das quais é possível levantar al guns dos problemas que assolavam a população colonial: doenças de pele; males venéreos, como a sífilis; verminoses variadas; problemas oculares; anemia; febres; chagas; tumores; dores de cabeça; paralisias; cólicas; males do estômago, do coração e dos ossos; mordidas de cobra; insônias, sem contar, é claro, as enfermidades epidêmicas, como varíola e outras ${ }^{21}$. D estacou-se desta Coleção de recei tas a célebre Triaga B rasílica, composta de dezenas de ervas, plantas, raízes, gomas, sais minerais e óleos, para cura de envenenamentos, ocasionados tanto por ervas e plantas como por animais, além de outras tantas enfermidades: quaisquer dores internas, verminoses intestinais, febres, doenças epidêmicas, doenças "de mulheres", etc. D e largo consumo no B rasil e na E uropa, vendida a preços altos, foi elaborada no Colégio da Bahia e gerou recursos consideráveis para a instituição ${ }^{22}$.

As boticas dos outros colégios jesuítas também integraram esta Cole ção, a exemplo dos Colégios de L isboa, É vora, M acau e Goa ${ }^{23}$. Além das

${ }^{20} \mathrm{~A}$ chamada "pedra infernal" (nitrato de prata) era produto do Colégio da Bahia, cuja virtude era "exterminar verrugas, consumir carnes supérfluas e calozas nas úlceras e para outros semelhantes efeitos". "Coleção de receitas...", op. cit., pp. 269-270, Serafim L eite, Serviços de saúde.., op. cit., p. 12.

${ }^{21}$ Idem, p. 13.

${ }^{22}$ L ourival Ribeiro, Medicina no B rasil colonial, op. cit., pp. 178-187.

${ }^{23} \mathrm{O}$ C olégio de São Paulo de G oa preparava em sua botica as "pedras cordeares", ou "pedras de G oa", cuja fórmula era de autoria do químico florentino Gaspar Antônio, trazendo rendimentos consideráveis para o C olégio por conta de sua exportação para a E uropa e para o O riente. Começaram a ser falsificadas e comercial izadas por al guns boticários de $G$ oa, levando a que o Provincial local da Companhia de J esus reivindicasse o monopólio de seu preparo ao Colégio, em 1691, apud Serafim L eite, Serviços de saúde.., op. cit., p. 11. 
suas próprias, os jesuítas incluíram ainda as elaboradas por médicos afamados, como C urvo Semedo, Jacob de Castro Sarmento, L uis G omes F erreira, J oão Cardoso de M iranda e outros ${ }^{24}$.

F oram obra dos jesuítas a fundação e a reforma de algumas instituições de saúde no Brasil. E m março de 1582, a armada do almirante espanhol D iogo $\mathrm{F}$ lores Baldez, que rumava para o $\mathrm{E}$ streito de $M$ agal hães, aportava no Rio de Janeiro com uma tripulação doentíssima: escorbuto, febres, beribéri, dentre outras, fazendo o Pe. Anchieta mobilizar-se para tratar dos enfermos num barracão toscamente construído na orla do M orro do Castelo. E mbora já existisse, desde os inícios da história da cidade, a Santa Casa da M isericórdia foi ampliada e reformada a partir deste episódio ${ }^{25}$. Já a Santa C asa de São L uís do M aranhão foi criada na última metade do século XVII, considerada pelo Pe. Antônio Vieira como fundamental, tendo que funcionar "perto da casa dos M issionários, aonde se curem todos os enfermos da Aldeia com toda a caridade a quem não tem suas casas por extrema miséria, e pouca caridade dos seus, a qual os nossos procurarão suprir" 26 .

Desafios

A nova colônia americana assistiu à chegada impiedosa de inúmeras moléstias trazidas pelos portugueses e, ainda, pelos escravos vindos de África, precariamente atochados nos tumbeiros desde finais do século XVI. Assolada por surtos epidêmicos de doenças como malária, sarampo, febre amarela, disenteria e varíola, contou com a enorme habilidade dos jesuítas na observação dos sintomas, na evolução destas moléstias e na aplicação da terapêutica possível. Todos os al deamentos indígenas na colônia foram alvo da ação jesuítica na área da medicina e da saúde. E m 1574, o Provincial I nácio de Tolosa determinou que em todas as aldeias fossem criadas enfermarias e casas isoladas, que funcionassem como hospital27. 0 trabal ho era intenso: além das epidemias e outras doenças, cuidavam também de índios feridos pelas guerras, de parturientes, drenavam pântanos para melhorarem as condições dos aldeamentos e reforçavam a alimentação dos doentes.

\footnotetext{
${ }^{24}$ Serafim L eite, H istória da Companhia deJ esus no B rasil..., op. cit., Tomo II , pp. 583-584.

${ }^{25} \mathrm{~L}$ ourival Ribeiro, M edicina no B rasil colonial, op. cit., p. 44.

${ }^{26}$ Idem, p. 51.

${ }^{27} \mathrm{~L}$ icurgo Santos F ilho, H istória geral da medicina..., op. cit., p. 126.
} 
J esuítas e M edicina no B rasil Colonial

E xemplo notável foi a passagem do Pe. J osé de Anchieta pelo B rasil, cuja correspondência deixou relatos impressionantes. Tendo como estímulo e exemplo o Pe. F rancisco X avier e sua atuação no O riente, chegou à Bahia em 1553, aos 20 anos, com o segundo Governador-Geral do Brasil, D uarte da Costa, e neste mesmo ano ajudou na fundação da vila de Piratininga, criando um colégio de nome "São Paulo", em homenagem ao apóstolo. E screvendo ao próprio I nácio de $L$ oyola, narrou as primeiras dificuldades desta empreitada: " $E$ aqui estamos às vezes mais de 20 dos nossos numa barraquinha de caniço e barro, coberta de palha (...). I sto é a escola, a enfermaria, o dormitório, refeitório, cozinha, dispensa" ${ }^{28}$. Anchieta aprendeu tupi, escreveu uma gramática, autos teatrais e criou uma "língua geral", no intuito de facilitar a catequese ${ }^{29}$. E screveu, em 1554, a alguns irmãos enfermos de Coimbra, que, em Piratininga, servia de médico e barbeiro, curando e sangrando muitos índios "dos quais viveram alguns de que se não esperava vida, por serem mortos muitos daquelas enfermidades" $30 . \mathrm{N}$ arrou em suas cartas o quão fundamentais eram os jesuítas para os gentios, não só no socorro "com as medicinas", mas também no fornecimento de alimentos, no quadro de escassez que grassava na colônia neste momento. E mesmo para os portugueses, que "parecem que não sabem viver sem nós outros, assim em suas enfermidades próprias, como de seus escravos". N os soldados da Companhia de J esus, bradava Anchieta, tinham "médicos, boticários e enfermeiros; nossa casa é a botica de todos, poucos momentos está quieta a campainha da portaria, uns indo, outros vindo, a pedir diversas coisas" ${ }^{31}$.

D escreveu com detal hes dezenas de animais, a exemplo das diversas espécies de cobras venenosas: sua aparência, como atacam, onde se escondem, de que modo o veneno atua e ainda o tempo de sobrevivência das vítimas. U ma delas era chamada de boicininga, que significa "cobra que tine", "paralizando com seu veneno a vista, o ouvido, o andar e todas as ações do corpo (...), até que no fim de vinte e quatro horas se expira". E m meio a esta multidão de répteis, porém, desabafou que "só o Senhor nos conserva incó-

\footnotetext{
${ }^{28} \mathrm{~L}$ opes Rodrigues, Anchieta ea medicina, Belo H orizonte, Apollo, 1934, p. 38.

${ }^{29}$ Alfredo Bosi, D ialética da colonização, São Paulo, Companhia das L etras, 1996.

${ }^{30} \mathrm{C}$ arta aos I rmãos enfermos em Coimbra. D e São Vicente, 1554, J osé de Anchieta, Cartas, informa ções, fragmentos históricos eser mões, Belo H orizonte, I tatiaia, 1988, pp. 141-142.

${ }^{31}$ Idem, pp. 239/40.
} 
Iumes, e confiamos mais nele do que em contra-veneno ou poder al gum humano; só descansamos em J esus, Senhor nosso, que é o único que pode fazer com que nenhum mal soframos, andando assim por cima de serpentes" 32 .

U m dos grandes desafios enfrentados pelos jesuítas na prática de suas artes médicas foram as epidemias de varíola que devastaram a população ameríndia ${ }^{33}$. Tendo atravessado os mares, trazida pelos colonizadores, iniciou seu flagelo no Brasil em 1559, na costa, para depois se alastrar para o norte. N o E spírito Santo, por exemplo, dizimou, neste ano, cerca de seiscentos escravos indígenas, e chegou ao auge em 1662, quando faleceram mais de 30 mil dos que estavam submetidos aos portugueses no litoral. Também foram incontáveis os que pereceram no sertão, fugidos das terríveis condições das regiões litorâneas, à medida que a epidemia se alastrava. $\mathrm{N}$ as aldeias jesuíticas, as perdas foram de um terço e, nos engenhos, a mortal idade foi igualmente devastadora ${ }^{34}$. 0 padre $L$ eonardo do Vale, numa cruzada inglória contra a doença, acudiu a muitos, narrando as mazelas vividas dramaticamente pelas comunidades ameríndias ${ }^{35}$. A observação arguta deste cotidiano devastador fê-los perceber variações da doença: al gumas brandas, de tratamento mais fácil, outras mais virulentas e mortíferas ${ }^{36}$.

Anchieta tratou-os com sangrias e com extirpação das partes do corpo já "corrompidas" pela doença, procedimentos, por sinal, considerados como os mais eficazes pelo médico Simão Pinheiro M ourão, quando, em 1694, escreveu o Tratado único das bexi gas esarampo, na época o trabal ho mais completo e original sobre o assunto. A chamada água cordial bezoártica contra bexigas esa rampo, cuja fórmula era de autoria do famoso C urvo Semedo, também foi recurso utilizado no tratamento da varíola, constando das boticas jesuíticas e citada na Col eção de várias receitas, como esta: flores de papoulas vermelhas, esquibas (excremento) recentes de cavalo, bezoártico do Curvo, arrobe de bagas de sabugo e água comum. É interessante observar que os

\footnotetext{
${ }^{32}$ C arta ao Padre G eraldo, de São Vicente, no último maio de 1560, idem, pp. 152-154.

${ }^{33} \mathrm{M}$ ary L indemann, M edicina esoci edadeno início da E uropa M oderna, L isboa, R eplicação, 2002, p. 49.

${ }^{34}$ Stuart Schwartz, Segredos internos. E ngenhos eescravos no B rasil colonial, São Paulo, Companhia das L etras, 1988, pp. 51-52.

35 I dem, p. 53.

${ }^{36} \mathrm{C}$ arta ao P rovincial G eral D iogo L ainez, de São Vicente, datada de janeiro de 1563, J osé de Anchieta, Cartas, informações, fragmentos..., op. cit., pp. 205-208.
} 
J esuítas e M edicina no B rasil Colonial

jesuítas, como já foi dito, faziam uso de terapêuticas diversas, fundamentados em tratados médicos importantes ${ }^{37}$.

Também implacável foi a epidemia de sarampo, que, em 1563, agravou a crise demográfica indígena, afetan do a economia colonial, nestes tempos dependente da mão-de-obra escravizada nos engenhos açucareiros e da produção de gêneros alimentícios nativos ${ }^{38}$.

M edicina indígena, pajés demônios

Os olhos dos jesuítas estavam diante de uma sociedade extremamente diferente, cujos costumes, crenças e ritos por vezes os assombraram, exigindo persistência e determinação ao lidar com o canibalismo, com a poligamia, com o incesto, com suas crenças e com a organização, para eles caóti$\mathrm{ca}$, do modo de vida do indígena. $\mathrm{O} \mathrm{N}$ ovo M undo povoava-se de ameríndios tidos como bárbaros, ferozes, quase animais, intensificando-se os propósitos jesuíticos de resgatá-los desta espúria condição ${ }^{39}$. N óbrega, indignado, via-os como "cães em se comerem e matarem, e são porcos nos vícios e na maneira de se tratarem", "gente de condição mais de feras bravas que de gente racional" 40. Para Anchieta, inclusive, a própria integração e convivência tranqüila do indígena com a natureza colonial, para ele avassaladora, perigosa e misteriosa, era claro indício de animalidade ${ }^{41}$.

À percepção brutal izada e animalesca dos indígenas, associou-se a visão demoníaca, freqüentemente referida nas considerações dos inacianos ao lidar com este outro mundo. Sua habitação era a própria visão do I nferno, como narrou F ernão Cardim, diante de tal ajuntamento de índios: "E como a gente é muita, costuma ter fogo de dia e noite, verão e inverno, porque o fogo é a sua roupa e eles são mui coitados sem fogo. Parece a casa um inferno ou labirinto, uns cantam outros choram, outros comem, outros fazem farinhas e vinhos, etc. e toda casa arde em fogos" ${ }^{42}$. A incompreensão daquele espa-

\footnotetext{
${ }^{37} \mathrm{~L}$ ourival Ribeiro, M edicina no B rasil colonial, op. cit., p. 148.

38 Stuart Schwartz, Segredos internos..., op. cit., p. 52.

${ }^{39}$ R onald Raminelli, I magens da colonização. A representação do índio, de Caminha a Vieira. São Paulo, E dusp/J orge Zahar, 1996, p. 54.

${ }^{40} \mathrm{~L}$ aura de M ello e Souza, 0 diabo ea terra..., op. cit., p. 64.

${ }^{41} \mathrm{~L}$ uiz F elipe Baeta $\mathrm{N}$ eves, 0 combate dos soldados deCristo..., op. cit., p. 54.

${ }^{42}$ F ernão Cardim, Tratados da terra e..., op. cit., p. 172.
} 
ço, gigantesco, cuja entrada eram "buracos", superpovoado, sem distinções de nenhuma espécie, sem ordem, sem hierarquias, sem divisões de tarefas aparentes, sem normas familiares, causou enorme espanto e a certeza de que os aldeamentos, estes sim, território cristão, corrigiriam estas distorções ${ }^{43}$. A ausência de leis, o desconhecimento total de regras, levando-os à exposição de seu corpo nu e à ingestão de outros, eram os responsáveis pelo sentimento de repúdio ao ameríndio44.

O utro exemplo do quão intenso foi o olhar demonológico dos jesuítas e de muitos cronistas leigos e eclesiásticos sobre o Brasil está na percepção das práticas mágico-religiosas dos gentios, cujos principais protagonistas eram os pajés, agentes do espaço do sagrado, mas também agentes satânicos. $A$ possibilidade de compreensão daqueles fenômenos estava na associação com os rituais sabáticos da feitiçaria européia, assimilando estes cronistas o que viam através de seus códigos culturais ${ }^{45}$. Assim, a empreitada hercúlea da catequese esbarrou ainda na ação nefasta do xamanismo tupi, destacandose, no conjunto destes ritos, variados procedimentos curativos, vistos pelos inacianos como ilegítimos e demonizados. E ste conflito se deu tanto no plano espiritual, como nas artes terapêuticas, pois os pajés eram considerados feiticeiros e embusteiros ${ }^{46}$. Citemos $N$ óbrega novamente, quando, em 1549, na I nformação da terra do B rasil, descreve um ritual das chamadas "santidades" ameríndias ${ }^{47}$ :

Acabando de falar ao feiticeiro, começam a tremer, principal mente as mulheres, com grandes tremores em seu corpo, que parecem demoninhadas (como de certo o são), deitando-se em terra, e escumando pelas bocas, e nisto lhes

\footnotetext{
${ }^{43}$ L uiz F elipe Baeta N eves, 0 combate dos soldados deCristo..., op. cit., pp. 124-127.

44 I dem, p. 54.

45 “A grande vedete da demonologia americana é o diabo: é el e que torna a natureza selvagem e indomável, é ele que confere os atributos da estranheza e da indecifrabilidade aos hábitos cotidianos dos ameríndios, é ele sobretu do que faz das práticas religiosas dos autóctones idolatrias terríveis e ameaçadoras, legitimando assim a estirpação pela força". L aura de M ello e Souza, I nferno atlântico. D emonol ogia e col onização - Sécul os XVI-XVI II , São Paulo, Companhia das L etras, 1993, p. 29.

${ }^{46}$ M axime H ubert, Í ndios e jesuítas no tempo das missões, São Paulo, Companhia das L etras, 1967.

${ }^{47}$ E stes rituais, envolvendo as práticas mágico-religiosas indígenas, imiscuídas ao cristianismo, foi brilhantemente estudada por R onaldo Vainfas, em A heresia dos índios. Catolicismo e rebeldia no B rasil colonial, São Paulo, Companhia das L etras, 1996.
} 
J esuítas e M edicina no B rasil Colonial

persuade o feiticeiro que então lhes entra a santidade; e a quem isto não faz tem-Iho a mal. D epois Ihe oferecem muitas coisas e em as enfermidades dos gentios usam também estes feiticeiros de muitos enganos e feitiçarias ${ }^{48}$.

D etentores do saber nas comunidades indígenas, o pajé era alvo importante do projeto missionário. E ra preciso desmascará-lo, mostrá-lo nos seus embustes e falsidades, apresentá-lo como instrumento demoníaco e também convertê-lo, abrindo espaço para o verdadeiro e único saber, que era do D eus cristão ${ }^{49}$. Suas práticas curativas foram duramente detratadas pelo próprio Anchieta:

Já não ousas agora servir-te de teus artifícios, perverso feiticeiro, entre povos que seguem a doutrina de C risto: já não podes com mãos mentirosas esfregar membros doentes, nem com lábios imundos chupar as partes do corpo que os frios terríveis enregelaram, nem as vísceras que ardem de febre, nem as lentas podragas nem os baços inchados. Já não enganarás com tuas artes os pobres enfermos que muito creram, coitados! $\mathrm{N}$ as mentiras do I nferno ${ }^{50}$.

\section{Cura ecatequese}

Os inacianos viam-se como médicos espirituais e corporais, expressando, assim, uma inequívoca correlação entre a cura dos corpos e a perspectiva da conversão à fé cristã ${ }^{1}$. 0 discurso jesuítico, presente nas várias correspondências, vai mostrar que o último suspiro de muitos foi precedido de batismos, como narrou Anchieta sobre o caso de uma índia, que, já sem esperanças de sobrevivência, pediu o sacramento e rapidamente recuperou a saúde. Anchieta dizia ainda que o batismo "apagava a malignidade das doenças", causando verdadeiros milagres de cura ${ }^{52}$.

\footnotetext{
${ }^{48} \mathrm{~L}$ aura de M ello e Souza, I nferno atlântico..., op. cit., p. 28.

49 "L úcifer é o pagé. E ste é o locutor infernal que é preciso calar". L uiz F elipe Baeta N eves, 0 combatedos sol dados de Cristo..., op. cit., p. 93.

50 I dem, p. 94.

${ }^{51}$ J osé de Anchieta, Cartas, informações, fragmentos..., op. cit., p. 185. N os relatos de sua ação missionária no Oriente, o $\mathrm{Pe}$. F rancisco de Souza explicitou que o número de convertidos seria bem mais elevado, se em cada uma das missões estivesse um bom cirurgião, impregnado "de fé, de fé cristã e de fé na cura que ainda hoje tantos prodígios obra em certas doenças". Pe. F rancisco de Souza, Orienteconquistado a J esus Cristo, L isboa, 1613; A na M aria Amaro, I ntrodução da medicina ocidental..., op. cit., pp. 94-95.

${ }^{52}$ J osé de Anchieta, Cartas, informações, fragmentos..., op. cit., p. 180.
} 
E m uma de suas cartas, escrita em 1554, contou que um índio fora gravemente ferido no braço. 0 sangue escorria-Ihe das veias sem parar, não havendo meio de estancá-lo e "depois de breve expiração de seus pecados recebeu o santíssimo corpo de C risto, e repentinamente o moribundo reviveu" ${ }^{33}$. A intenção era mostrar a recompensa da cura pela conversão ao cristianismo, como afirmou em outra carta, de 1556, explicitando claramente esta correlação: "fazemos isto na intenção de preparar o recebimento do batismo (...), por igual motivo é que desejamos assistir as parturientes a fim de batizar mãe e filho. Assim acontece atender-se a salvação do corpo e da alma" 54 .

D e importância fundamental para a catequese, o batismo era o signo por excelência de um novo e verdadeiro nascimento, que não é físico, mas espiritual. Signo da aceitação da conversão e de sucesso, para os missionários, de seu papel de evangelizadores ${ }^{55}$. $\mathrm{N}$ as cartas jesuíticas datadas dos anos difíceis em que a varíola devastou parte da população indígena, para além do trabal ho insano de percorrer léguas e léguas acudindo os doentes, a angústia dos padres voltava-se para o grande número dos que faleciam sem os sacramentos.

A associação entre vida, saúde, conversão e salvação pressupunha o oposto: a recusa da fé cristã poderia levar à morte. E screvendo em 1560, de Piratininga, ao Provincial Geral da Companhia, contou Anchieta que, chegando a uma aldeia para acudir a um índio gravemente enfermo, "para Ihe dar algum remédio, principalmentepara sua alma" (grifos meus), persuadiu-o a que aceitasse o batismo e abandonasse seus "costumes passados". R ebelde, indignado, negou veementemente a oferta por várias vezes, até que, já bem agravado seu estado, "e permanecendo na mesma obstinação, no outro dia, morreu" 56 .

A cura trazida pelo jesuíta, intermediada pelo batismo, era a legítima, proporcionada, em última instância, pelo D eus cristão ${ }^{57}$. A efervescência dos

\footnotetext{
${ }^{53}$ B reve narração das cou sas relativas aos C olégios e R esidências da Companhia nesta Província Brasílica, no ano de 1584, idem, p. 217.

${ }^{54}$ I dem, p. 147.

${ }^{55} \mathrm{~L}$ uiz F elipe Baeta N eves, 0 combatedos soldados deCristo..., op. cit., p. 73.

${ }^{56}$ J osé de Anchieta, Cartas, informações, fragmentos..., op. cit., pp. 155-156.

57 “U ma doença incurável desaparece com o batismo, a comunhão que opera prodígios, ou até o fato de o jesuíta colocar as mãos sobre o índio; de outra parte, são os objetos de devoção". M axime H ubert, op. cit., p. 149.
} 
J esuítas e M edicina no B rasil Colonial

costumes ameríndios, no discurso dos padres da Companhia, poderia ser punida com o castigo divino, por doenças e morte, " porque os que se apartaram de nós outros não fazem senão morrer aqui e acolá, por suas malditas habitações, sem confissão, uns amancebados; outros levados e comidos por seus contrários" 58 .

E m síntese, a vastíssima documentação jesuítica descreveu lendas indígenas, línguas, tipo físico dos nativos, seus costumes e modo de vida, religião, embates entre tribos. Ao longo do tempo e dos caminhos que trilharam para o estabelecimento e a consolidação da Companhia de J esus no B rasil, fundando colégios e seminários, e tentando cumprir com o máximo êxito sua missão evangelizadora e educacional, perceberam o Brasil com os ol hos de natural istas, botânicos, zoólogos, geólogos, etnógrafos, médicos, sangradores, cirurgiões. Os padres da Companhia de J esus cumpriram com precisão seu modelo de atuação, constituindo-se um de seus princípios básicos a capacidade de serem "polivalentes", realizando um pouco de tudo para o bem correr de sua divina missão ${ }^{59}$.

Para além do que vinha da farmacopéia européia e oriental, a natureza brutalizada e violenta do mundo colonial ofereceu aos inacianos ervas, raízes, enfim, os remédios para as curas, auxiliados pel os conhecimentos dos nativos, graças a quem os jesuítas adensaram suas fórmulas e práticas curativas. $\mathrm{N}$ o entanto, foram estas mesmas práticas que serviram de apoio ao projeto catequético inaciano, projeto aculturador, que, em nome da fé cristã, marcou presença decisiva no mundo colonial.

\footnotetext{
${ }^{58}$ J osé de Anchieta, Cartas, informações, fragmentos..., op. cit., p. 189.

${ }^{59}$ Célia C ristina Tavares da Silva, J esuítas el nquisidores em G oa, L isboa, R oma E ditora, 2004, p. 97.
} 